\title{
Evaluation of helping babies breathe and essential care for every baby training in southern nations nationalities and people's region, Ethiopia: applying a Kirkpatrick training evaluation model
}

\author{
Lalisa Chewaka Gamtessa ${ }^{1 *} \mathbb{D}$, Firew Tiruneh Tiyare ${ }^{2}$ and Kindie Mitiku Kebede ${ }^{3}$
}

\begin{abstract}
Objective: The aim of this evaluation was to assess the effectiveness of helping baby breathe (HBB) and essential care for every baby (ECEB) training program that has been implemented in southern nations nationalities and people's region (SNNPR), Ethiopia.

Result: The mean trainees' satisfaction score was 32.88 (SD \pm 2.68 ). The majority (93.88\%) of the trainees scored $\geq$ mean. All trainees expressed that all parts of the training were important but the updated parts of the training were most useful to them. The mean knowledge score of trainees for HBB training increased from 64.42 $(S D \pm 17.43)$ before the training to $80.71(S D \pm 14.36)$ after the training. The increment was statistically significant at $p<0.001$. For ECEB training, the mean knowledge score of the trainees was increased from 59.10 (SD \pm 13.18 ) before the training to 73.73 ( $S D \pm 14.17$ ) after the training. The improvement was statistically significant at $p<0.001$.
\end{abstract}

Keywords: Helping babies breathe, Essential care for ever baby, Knowledge, Training, Satisfaction, Ethiopia

\section{Introduction}

Globally, neonatal mortality declined by $51 \%$ between 1990 and 2017. Though the reduction was significant, it was estimated that 27.8 million neonates will die between 2018 and 2030 [1]. In Ethiopia, neonatal mortality rate (NMR) was high and accounted for 30 per 1000 live births in 2019 [2].

Studies have shown that locally adaptable trainings like ECEB and HBB can reduce neonatal and still birth rate [3-5]. The ECEB and HBB training was developed by the American Academy of Pediatrics (AAP) and its partners.

\footnotetext{
*Correspondence: Ialisachewaka@gmail.com

1 Department of Nursing, College of Medicine and Health Sciences,

Mizan-Tepi University, Mizan-Aman, Ethiopia

Full list of author information is available at the end of the article
}

The training intends to equip health care providers, with an optimum basic resuscitation skill and essential care after birth [6, 7]. This training significantly improved the knowledge and skill of health care providers in resource limited settings [8-10].

Moreover, study findings in resource limited countries showed that the training has resulted in a high level of satisfaction among the trainees $[9,11,12]$. Despite a high level of satisfaction, trainees recommended for extension of the training duration, incorporation of real life demonstrations, videos, and advanced resuscitation skills $[9$, 12].

ECEB and HBB training has been provided in Ethiopia since 2018. Nevertheless, the effect of this training on the level of trainees' satisfaction, knowledge, and skill has not been yet reviewed. Evaluating training is as important as

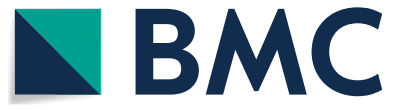

(c) The Author(s) 2020. This article is licensed under a Creative Commons Attribution 4.0 International License, which permits use, sharing, adaptation, distribution and reproduction in any medium or format, as long as you give appropriate credit to the original author(s) and the source, provide a link to the Creative Commons licence, and indicate if changes were made. The images or other third party material in this article are included in the article's Creative Commons licence, unless indicated otherwise in a credit line to the material. If material is not included in the article's Creative Commons licence and your intended use is not permitted by statutory regulation or exceeds the permitted use, you will need to obtain permission directly from the copyright holder. To view a copy of this licence, visit http://creativeco mmons.org/licenses/by/4.0/. The Creative Commons Public Domain Dedication waiver (http://creativecommons.org/publicdomain/ zero/1.0/) applies to the data made available in this article, unless otherwise stated in a credit line to the data. 
providing training because it helps to know the degree to which training objectives were achieved. Therefore, this evaluation was aimed to assess the effect of $\mathrm{HBB}$ and ECEB training on the satisfaction and knowledge of trainees in SNNPR using a Kirkpatrick training evaluation model [13].

\section{Main text \\ Methods \\ Study setting and area}

The evaluation was conducted on the training given in two Hospitals in SNNPR selected by the program facilitators. These are Mizan-Tepi University Teaching Hospital and Sawula General Hospital which are located at $585 \mathrm{~km}$ and $514 \mathrm{~km}$ away from Addis Ababa, respectively.

\section{Design}

A formative evaluation was conducted by applying the Kirkpatrick training evaluation model. The model is known well world-wide and comprises four levels. The four levels are reaction (level 1), learning (level 2), behavior (level 3), and result (level 4) [13]. Further detail about the Kirkpatrick model is presented as Additional file 1.

\section{Trainers and trainees}

The Village Health Partnership provided training of trainers for six senior lecturers on $\mathrm{HBB}$ and ECEB training. The six trainers (3 pediatric Nursing specialists, 2 General Practitioners, and 1 Clinical Midwife) provided the training for five rounds starting from 2018-2019.

A total of 98 health care providers encompassing nurses, midwives, anesthetists, and health officers who came from Gamo, Goffa, and Bech-Sheko Zones of SNNPR were trained. These trainees were those who were involved in newborn care, and selected by their respective health facilities. The training was given for four days by dividing the trainees into five sub-groups with a ratio of one trainer to five trainees as per the protocol.

\section{$H B B$ and ECEB training}

$\mathrm{HBB}$ and ECEB training is an evidence based program developed by AAP and its partners to train health care providers to equip them with knowledge and proper skill of neonatal resuscitation in resource limited countries $[6,7]$. The HBB training consists of four main lessons: preparation for birth, routine care, the Golden minute, and ventilation with normal or slow heart rate. The ECEB training addresses continuing skin to skin care, initiation of breast feeding, provision of eye and cord care, provision of vitamin $\mathrm{K}$, examination of the baby, measurement of temperature, weighing, and classifying the baby [7]. The training contains action plan, provider guide, facilitator guide, flipcharts, and materials for demonstration.

\section{Evaluation of knowledge}

Following necessary orientations, a pre-test with 18 standardized multiple choice questions was given to assess the knowledge of trainees about the HBB course contents. Immediately after the completion of $\mathrm{HBB}$ training, the trainees were re-evaluated using similar 18 multiple choice questions used in the HBB pre-test. Similarly, before starting the ECEB training, a pre-test with 25 standardized multiple choice questions was given to assess the knowledge of trainees about ECEB course contents. After completion of the ECEB training, the trainees were re-evaluated using similar 25 multiple choice questions used in ECEB pre-test.

\section{Evaluation of satisfaction}

The trainees' satisfaction was evaluated using seven standardized questions with five likert scales arranged from strongly disagree to strongly agree along with two open ended questions. The trainees' were asked their satisfaction after completing the HBB and ECEB training.

\section{Operational definitions}

Knowledge: The immediate knowledge acquired as a result of the training measured by comparing the mean score of pre- and post-test results.

Satisfaction: Trainees who scored mean and above the mean were considered as satisfied but otherwise they were considered as unsatisfied.

\section{Data collection}

Data were obtained from the reporting documents of $\mathrm{HBB}$ and ECEB training deposited at Mizan-Tepi University Educational Development Center (EDC). EDC is responsible for coordinating the $\mathrm{HBB}$ and $\mathrm{ECEB}$ training. The trainees' profile, their knowledge and satisfaction scores are available at the EDC. Two trained BSc nurses collected data using the data extraction formats presented as Additional files 2, 3, 4, 5 .

\section{Statistical analysis}

Data were entered into Epi Info 7 and imported to SPSS version 21.0 for analysis. Descriptive statistics (frequencies and percentages) were computed to describe trainees' socio-demographic characteristics and level of satisfaction. A Paired Samples T-test was used for comparing the pre-test and post-test mean knowledge score difference of the trainees. The statistical significance was determined at $\mathrm{p}$-value $<0.05$. 


\section{Results}

Socio-demographic characteristics of trainees

More than two thirds of the trainees were females. The majority of trainees were nurses and midwives while anesthetists accounted for the smallest proportion of the trainees (Table 1).

\section{Trainees' satisfaction}

The mean score of likert items used in evaluating satisfaction of trainees was 32.88. The majority of trainees scored $\geq$ the mean. All trainees mentioned that all parts of the training were important but they replied that the updated parts of the $\mathrm{HBB}$ and ECEB training were most useful for them. The majority of trainees were satisfied with the training, but a few trainees remained undecided on item 4 and item 7 (Table 2).

\section{Trainees' knowledge}

The knowledge of the trainees improved after the training. For the $\mathrm{HBB}$ training, the mean knowledge score of the trainees was increased from 64.42 (SD \pm 17.43 ) before the training to $80.71(\mathrm{SD} \pm 14.36)$ after the training. This increment was statistically significant; $t \quad(97)=11.146$, $p<0.001$. For the ECEB training, the mean knowledge score of the trainees was increased from 59.10

Table 1 Socio-demographic characteristics of trainees in SNNPR, Ethiopia, 2018-2019

\begin{tabular}{llll}
\hline Variables & & Frequencies & Percentages \\
\hline Sex & Male & 32 & 32.7 \\
& Female & 66 & 67.3 \\
Health facility & Hospital & 47 & 48.0 \\
& Health center & 51 & 52.0 \\
Qualification & Degree & 60 & 61.2 \\
& Diploma & 38 & 38.8 \\
Professionals & Nurses & 30 & 30.6 \\
& Midwives & 55 & 56.1 \\
& Health officers & 9 & 9.2 \\
& Anesthetists & 4 & 4.1 \\
\hline
\end{tabular}

$(\mathrm{SD} \pm 13.18)$ before the training to $73.73(\mathrm{SD} \pm 14.17)$ after the training. This improvement was statistically significant; $(\mathrm{t}(97)=11.684, p<0.001$.

\section{Discussion}

Evaluation is very important to determine the effectiveness of programs. In the current evaluation, the $\mathrm{HBB}$ and ECEB training significantly improved trainees' knowledge and nearly all trainees were satisfied with the training.

In this evaluation, trainees' level of satisfaction was high. This finding is in line with several evaluation studies in resource limited countries [9, 12, 14]. Though majority of the trainees were satisfied with the training, a few trainees remained undecided on item 4 (facilitators were fair and friendly) and item 7 (teaching aids were useful). Therefore, to further enhance the trainees' satisfaction, programmers and trainers should consider these two items. Moreover, all the trainees mentioned that the updated parts of HBB and ECEB training were most important. The updated parts include rational clinical practices related to suction, ventilation, cord care, and benefits of skin to skin $[6,7]$. Therefore, focusing on these areas may further increase trainees' satisfaction level.

The trainees' knowledge score was also significantly improved immediately after the training. Several studies revealed that $\mathrm{HBB}$ and $\mathrm{ECEB}$ training significantly improved trainees' knowledge [9, 10, 12, 14, 15].

\section{Conclusion}

The $\mathrm{HBB}$ and ECEB training resulted in a significant increase in knowledge. Nearly all the trainees were satisfied by the training. More emphases should be given to the updated parts of the HBB and ECEB training as trainees expressed these parts were most useful.

\section{Limitations}

The current evaluation exclusively focused on the level 1 (satisfaction) and level 2 (knowledge) of Kirkpatrick training evaluation model. We did not evaluate long-term

Table 2 Trainees satisfaction across items in SNNPR, Ethiopia, 2018-2019

\begin{tabular}{|c|c|c|c|c|c|c|}
\hline & Items & Strongly agree & Agree & Undecided & Disagree & Strongly disagree \\
\hline 1 & For the work, I do, the training was appropriate & $74(75.51 \%)$ & $24(24.49 \%)$ & $0(0.00 \%)$ & $0(0.00 \%)$ & $0(0.00 \%)$ \\
\hline 2 & Training facilities and arrangements were satisfactory & $67(68.37 \%)$ & $31(31.63 \%)$ & $0(0.00 \%)$ & $0(0.00 \%)$ & $0(0.00 \%)$ \\
\hline 3 & The facilitators were knowledgeable and skilled & $67(68.37 \%)$ & $31(31.63 \%)$ & $0(0.00 \%)$ & $0(0.00 \%)$ & $0(0.00 \%)$ \\
\hline 4 & The facilitators were fair and friendly & $60(61.22 \%)$ & $36(36.74 \%)$ & $2(2.04 \%)$ & $0(0.00 \%)$ & $0(0.00 \%)$ \\
\hline 5 & The Training updated my knowledge and skills & $59(60.20 \%)$ & $39(39.80 \%)$ & $0(0.00 \%)$ & $0(0.00 \%)$ & $0(0.00 \%)$ \\
\hline 6 & Training objectives were met & $73(74.49 \%)$ & $725(25.51 \%)$ & $0(0.00 \%)$ & $0(0.00 \%)$ & $0(0.00 \%)$ \\
\hline 7 & Teaching aids were useful & $83(84.69 \%)$ & $12(12.24 \%)$ & $3(3.06 \%)$ & $0(0.00 \%)$ & $0(0.00 \%)$ \\
\hline
\end{tabular}


effect of the training due to resource constraints. Furthermore, the findings of this study should be cautiously interpreted as the sample size was small.

\section{Supplementary Information}

The online version contains supplementary material available at https://doi. org/10.1186/s13104-020-05394-7.

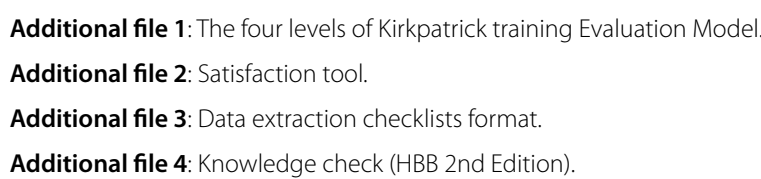

\section{Abbreviations}

A.A: Addis Ababa; AAP: American Academy of Pediatrics; Cl: Confidence interval; ECEB: Essential care for every baby; HBB: Helping babies breath; SD: Standard deviation; SNNPRs: South nations nationalities and peoples' regions.

\section{Acknowledgements}

We would like to thank Mizan-Tepi University, College of Health Sciences for providing us necessary support during this study.

\section{Author's contributions}

All authors equally participated on conception, study design, acquisition of data, analysis, interpretation, and a critical review of the document. All authors read and approved the final manuscript.

\section{Funding}

Not applicable.

\section{Availability of data and materials}

All the datasets used and or analyzed during the current study are available from a primary author on a reasonable request at lalisachewaka@gmail.com.

\section{Ethics approval and consent to participate}

This study was conducted with permission from the College of Medicine and Health Sciences, Academic, and Research Directorate (Ref No.: MTU/ CHS/996/12). Nonetheless, as the data used for this particular study was secondary type, the consent to participate was not applicable.

\section{Consent to publication}

Not applicable.

\section{Competing interests}

The authors declare that there is no competing interest.

\section{Author details}

${ }^{1}$ Department of Nursing, College of Medicine and Health Sciences, MizanTepi University, Mizan-Aman, Ethiopia. ${ }^{2}$ Department of Midwifery, College of Medicine and Health Sciences, Mizan-Tepi University, Mizan-Aman, Ethiopia.

${ }^{3}$ Department of Public Health, College of Medicine and Health Sciences,

Mizan-Tepi University, Mizan-Aman, Ethiopia.

Received: 21 August 2020 Accepted: 24 November 2020

Published online: 17 December 2020

\section{References}

1. Hug L, Alexander M, You D, Alkema L. National, regional, and global levels and trends in neonatal mortality between 1990 and 2017, with scenariobased projections to 2030: a systematic analysis. Lancet Glob Heal. 2019;7(6):e710-20. https://doi.org/10.1016/S2214-109X(19)30163-9.

2. ICF EPHI (EPHI) [Ethiopia]. Ethiopian Public Health Institute (EPHI) [Ethiopia] and ICF. 2019. Ethiopia Mini Demographic and Health Survey 2019: Key Indicators. Rockville, Maryland, USA: EPHI and ICF. 2019.

3. Garces A, Parida S, Althabe F, Mcclure EM, Ed M, Derman RJ, et al. Newborn-care training and perinatal mortality in developing countries. N Engl J Med. 2010;362:614-23.

4. Goudar SS, Dhaded SM, Mcclure EM, Derman RJ, Patil D, Mahantshetti NS, et al. ENC training reduces perinatal mortality in Karnataka, India ENC training reduces perinatal mortality in Karnataka India. Randomized Controlled Trail. 2011;25:568-74.

5. Chomba E, Mcclure EM, Wright LL, Waldemar A. Effect of WHO newborn care training on neonatal mortality by education. NIH Public Access. 2009;8(5):300-4.

6. AAP. Helping Babies Breathe, 2nd Edition Update Guide What's new on the HBB 2nd Edition Action Plan? 2015; pp. 1-9. Available from: https:// www.hbs.aap.org. Accessed June 2020

7. AAP. Helping babies survive: essential care for every baby provider guide [Internet]. 2014. Available from: https://www.aap.org. Accessed June 2020

8. Mersha A, Shibiru S, Gultie T, Degefa N, Bante A. Training and wellequipped facility increases the odds of skills of health professionals on helping babies breathe in public hospitals of Southern Ethiopia: crosssectional study. BMC Health Serv Res. 2019;19(1):1-12.

9. Seto TL, Tabangin ME, Josyula S, Taylor KK, Vasquez JC, Kamath-Rayne BD. Educational outcomes of helping babies breathe training at a community hospital in Honduras. Perspect Med Educ. 2015:4(5):225-32.

10. Thukral A, Lockyer J, Bucher SL, Berkelhamer S, Bose C, Deorari A, et al. Evaluation of an educational program for essential newborn care in resource-limited settings: essential care for every baby. BMC Pediatr. 2015:15:71. https://doi.org/10.1186/s12887-015-0382-z.

11. Maharjan U, Rajbanshi L, Dhungana GP. Effectiveness of helping babies breathe (hbb) training on knowledge: original research article. J Chitwan Med Coll. 2015:2014:37-40.

12. Singhal N, Lockyer J, Fidler H, Keenan W, Little G, Bucher S, et al. Helping babies breathe: global neonatal resuscitation program development and formative educational evaluation. Resuscitation. 2012;83(1):90-6. https:// doi.org/10.1016/j.resuscitation.2011.07.010.

13. Kirkpatrick BJ. The Kirkpatrick four levels ${ }^{T M}$ : a fresh look after 50 years the Kirkpatrick four levels ${ }^{\text {TM }}$ : a fresh look after 50 years the day of reckoning has arrived. Kirkpatric Partners; 2009.

14. Musafili A, Ess B. Evaluating helping babies breathe: training for healthcare workers at hospitals in Rwanda. Acta Paediatr Int J Paediatr. 2013;102:34-8.

15. Sami S, Kerber K, Tomczyk B, Amsalu R, Jackson D, Scudder E, et al. "You have to take action": changing knowledge and attitudes towards newborn care practices during crisis in South Sudan. Reprod Health Matters. 2017;25(51):124-39.

\section{Publisher's Note}

Springer Nature remains neutral with regard to jurisdictional claims in published maps and institutional affiliations. 